\title{
EDUCAÇÃO À DISTÂNCIA NO CONTEXTO DA EDUCAÇÃO ESPECIAL INCLUSIVA: NARRATIVAS DE ALUNOS SURDOS
}

\author{
Alexandre Moura Lima Neto \\ Alessandra Anchieta Moreira Lima de Aguiar ${ }^{2}$
}

RESUMO: A educação especial, na perspectiva da educação inclusiva, enfrenta muitos desafios, sobretudo no que se refere à inserção e permanência da pessoa com deficiência nos espaços educacionais. Mesmo com dispositivos legais narrando acerca de orientações para estes sujeitos estarem nos espaços educacionais, há entraves impeditivos ao processo de escolarização aconteça de forma eficiente. Com o avanço das tecnologias, novas formas de educação surgem, entre estas a Educação à distância $(\mathrm{EaD})$, que para muitos significa oportunidade de construção profissional, com agilidade e flexibilidade de tempo e espaço, sendo este aspecto discutido neste trabalho, sob a perspectiva de alunos surdos que realizaram atividades acadêmicas em ambientes virtuais. O trabalho descreve possíveis dificuldades e experiências dos estudantes surdos, em $\mathrm{EaD}$, agregando discussões acerca das possibilidades desta modalidade para o processo de ensino e de aprendizagem do sujeito surdo. $\mathrm{O}$ estudo estruturou-se a partir de pesquisa bibliográfica e de campo, tendo por base os pressupostos de Mazzzotta (2001), Skliar (2016), Chahini (2016), Lopes (2017), entre outros. Os resultados apontam que as plataformas dos cursos à distância são de fácil manuseio e compreensão; notou-se ainda, que os surdos da pesquisa não encontraram dificuldades nesta modalidade de ensino, e em sua maioria, destacaram que a comunicação pela escrita os aproximou dos demais alunos ouvintes, favorecendo o sentimento de inclusão através dos ambientes virtuais. Todavia, a ausência de um espaço em Libras foi uma questão pontuada, mas que subjaz pela atenção que tutores e professores ofertam aos estudantes surdos.

\footnotetext{
${ }^{\mathrm{I}}$ Mestrando em Cultura e Sociedade - Universidade Federal do Maranhão- UFMA. Professor Universitário e Membro do Grupo de Pesquisa em Patrimônio Cultural (UFMA/CNPq). http://lattes.cnpq.br/1706282255569486. E-mail: alexandrenetoadv@hotmail.com

2 Mestra em Meio Ambiente (UniCeuma). Professora Universitária (UniCEUMA). http://lattes.cnpq.br/6325229077291069. 
Palavras-chave: Educação especial. Educação Inclusiva. EaD. Surdos.

ABSTRACT: Special education, from the perspective of inclusive education, faces many challenges, especially regarding the insertion and permanence of people with disabilities in educational spaces. Even with legal provisions narrating about guidelines for these subjects to be in educational spaces, there are obstacles preventing the schooling process from happening efficiently. With the advancement of technologies, new forms of education emerge, including Distance Education ( $\mathrm{EaD})$, which for many means an opportunity for professional construction, with agility and flexibility of time and space, and this aspect is discussed in this work, from the perspective of deaf students who performed academic activities in virtual environments. The work describes possible difficulties and experiences of deaf students in $\mathrm{EaD}$, adding discussions about the possibilities of this modality for the teaching and learning process of the deaf subject. The study was structured from bibliographical and field research, based on the assumptions of Mazzzotta (2001), Skliar (2016), Chahini (2016), Lopes (2017), among others. The results show that the platforms of distance courses are easy to handle and understand; it was also

noted that the deaf in the research did not find difficulties in this type of teaching, and most of them highlighted that communication through writing brought them closer to other hearing students, favoring the feeling of inclusion through virtual environments. However, the absence of a space in Libras was an issue highlighted, but that underlies the attention that tutors and teachers offer to deaf students.

Keywords: Special education. Inclusive Education. EaD. Deaf. I INTRODUÇÃO

A história da educação brasileira demonstra avanços em diversas modalidades, entre estas, a educação especial, que tem buscado a garantia de acesso e permanência ao segmento formado por pessoas com deficiência que, geralmente, é colocada às margens das políticas educacionais, mesmo diante da Constituição Federal Brasileira (1998) a qual dispõe que a educação é um direito de todos.

A educação especial há muito vem sendo discutida, em razão de seu principal objetivo, qual seja, possibilitar a inserção de estudantes com deficiência ou necessidades educacionais especializadas nas escolas regulares, a partir do pressuposto que esta inclusão é condição precípua para a participação social e exercício da cidadania. Entre os 
dispositivos legais que orientam acerca da presença de estudantes com deficiência nas salas de aula comum, assim como sobre as metodologias utilizadas, percebe-se ainda algumas fragilidades nesta modalidade de ensino.

Considerando-se, pois, a realidade em que vivem as pessoas com deficiência, no Brasil, especialmente no tocante às políticas de educação especial, sob a perspectiva da educação inclusiva, este trabalho tem como objetivos discutir as estratégias utilizadas para garantir o acesso ao conhecimento aos alunos surdos em modalidade de educação a distância (EaD), discorrendo-se a respeito de estratégias que possibilitem a inclusão destes indivíduos, assim como aludindo-se sobre possíveis dificuldades e perspectivas, a partir dos relatos dos próprios estudantes da $\mathrm{EaD}$.

A escolha pela temática, em questão, justifica-se pela amplitude da modalidade de ensino à distância, com crescente número de adeptos, o que torna importante investigar os sujeitos surdos nos espaços virtuais acadêmicos. Considera-se que embora a educação especial tenha apresentado muitos esforços congregados e resultados positivos, a exemplo da Lei n. Io. 436/2002, regulamentada pelo Decreto 5.626/2005 conhecida como Lei das Libras, os resultados alcançados ainda florescem de modo tímido.

O estudo foi organizado com base em pesquisa bibliográfica, iniciada a partir de uma aproximação amiúde com o tema, tendo como base os pressupostos de Mazzzotta (2001), Skliar (2016), Chahini (2016), Lopes (2017), entre outros. Em um segundo momento, partiu-se para uma pesquisa de campo, a qual se deu com três estudantes surdos que fizeram parte de cursos de nível superior na modalidade EaD. As entrevistas aconteceram de forma individual e quanto à abordagem escolheu-se, a pesquisa qualitativa, que segundo Marconi e Lakatos (2017) pressupõe a análise e interpretação de aspectos mais profundos da complexidade dos sujeitos em sociedade.

Os resultados apresentados mostraram que os alunos surdos têm sido adeptos às plataformas digitais e não tiveram grandes dificuldades nos cursos à distância. Inferiu-se ainda que os espaços virtuais, para estes sujeitos, têm sido considerados inclusivos, e segundo a análise de dados, a aproximação com os demais alunos, professores e tutores tem sido possibilitada pela interação virtual. 


\section{EDUCAÇÃO ESPECIAL NA PERSPECTIVA INCLUSIVA: CONSIDERAÇÕES CONCEITUAIS E DISPOSITIVOS LEGAIS}

O percurso da educação, segundo Rogalski (2010) vem evidenciando maior preocupação com as questões da educação especial, especialmente após a década de 1970, quando esta passou a ser discutida por instituições públicas, privadas e órgãos políticos normativos. Anterior a esta data os estudantes com deficiência não frequentavam a escola regular, não faziam parte do sistema educacional tradicional. Seu acesso à educação se dava por meio da inserção em escolas ou classes especiais, formadas completamente por pessoas com deficiência, conforme aponta Miranda (2003).

Nessa acepção, torna-se essencial demarcar que educação especial e educação inclusiva, embora muitas vezes tidas como sinônimos, trata-se de fenômenos distintos. Para Kierkegaard (2006), a educação especial é uma modalidade que busca atender as pessoas com alguma especificidade educacional, mas ainda de forma separada dos demais alunos, sendo pensada inicialmente para propiciar educação a todos, mas que teve e tem suas fragilidades, as quais como bem afirmam Raiça e Oliveira (2007), em vez de estimular o desenvolvimento destes alunos, acabou por criar uma barreira psicológica, na qual as

diferenças físicas e intelectuais evidenciaram-se fazendo com que a discriminação e a rejeição muitas vezes fizessem parte da trajetória escolar dos alunos com deficiência.

A educação inclusiva, segundo Skliar (2016) trata-se de um movimento no qual as concepções destacam a necessidade de a escola oferecer condições que beneficiem o desenvolvimento dos alunos com especificidades, sendo descrito por Kierkegaard (2006) como um movimento atrelado ao conceito integrador, entre as diversas categorias que valorizam a diversidade. Vale ressaltar que se considera neste trabalho educação inclusiva enquanto concepção que permite ao aluno, ir além do espaço escolar, em termos de construção de saberes, sendo o acesso ao conhecimento necessário para a edificação eficiente de seu processo educacional.

Nesta concepção, Elias et al. (2012) concordam que a esfera escolar inclusiva demanda a efetivação de currículos adequados, bem como a prática profissional flexível, na perspectiva de materialização da inclusão dos sujeitos. Sobre a questão, os autores salientam ainda: 
O ensino batizado na perspectiva inclusiva ressignifica o papel do professor enquanto educador, seja na escola, na educação e em práticas pedagógicas que são usuais no contexto excludente em diversos níveis de ensino. Chama-se a atenção para o argumento - frequentemente utilizado por docentes para resistir a algumas práticas inclusivas - de que não estão ou não foram preparados para receber alunos com necessidades específicas de aprendizado (ELIAS et al., 2012, p 50).

Nesta acepção, verifica-se, pois, que incluir está para além do que propõe os aparatos legais da educação especial; envolve atores, tais como professores e demais profissionais, em instituições educacionais, partindo da premissa de que estes estejam preparados para o processo de ensino e de aprendizagem de seus alunos. Envolve também resoluções de problemas como os elementos físicos da esfera escolar enquanto barreiras em determinadas especificidades de mobilidade ou aspectos comunicacionais, por exemplo. Corroborando às palavras de Chahini (2016) quando a autora demarca a necessidade de ações atitudinais, sendo este um ponto crucial para tal perspectiva de educação.

Voltando-se para os dispositivos legais, a partir da década de 1990, os princípios educacionais oriundos da Conferência Mundial de Educação para Todos (1990), assim como da Declaração de Salamanca (1994), que discorriam acerca da garantia de acesso e permanência nas escolas das então chamadas pessoas com necessidades educacionais especiais (NEE), buscando propiciar também a efetivação do direito à educação com qualidade, ainda que tais princípios não tenham sido colocados em prática, em sua totalidade, tampouco se constituam garantias a uma educação, de fato, inclusiva, pois as condições educacionais do segmento ainda eram bastante incipientes, como afirma Mendes (2010).

Os anos 2000 trazem novos rumos à educação especial no Brasil, pois, a partir de então, o País cria leis mais específicas, em relação a temas tratados no contexto da educação especial, o que significa importantes avanços no tocante às políticas educacionais. Convém destacar que as Diretrizes Nacionais se constituíram primordialmente, haja vista estas terem afirmado a perspectiva inclusiva enquanto elemento intrínseco às políticas de Educação Especial no País (BRASIL, 2008).

Outro importante dispositivo foi o Decreto № 6.571/2008, que atualmente encontra-se revogado pelo Decreto $\mathrm{N}^{\circ}$ 7.6II de 20II, o qual dispõe acerca do atendimento Educacional Especializado, que entre outras coisas discorre sobre o dever do Estado, em vista de efetivações. O já mencionado Decreto evidencia ainda, a garantia de um sistema 
inclusivo em todos os níveis, preferencialmente em rede regular de ensino e no que diz respeito ao contexto da surdez faz referência em seu Artigo I으, parágrafo $2^{\mathrm{o}}$ que, "no caso dos estudantes surdos e com deficiência auditiva serão observadas as diretrizes e princípios dispostos no Decreto no 5.626, de 22 de dezembro de 2005” (BRASIL, 20II, não paginado), que será tratado detalhadamente mais à frente e ainda neste estudo.

A educação inclusiva é conceituada pela Política Nacional de Educação Especial na Perspectiva da Educação Inclusiva, no contexto dos direitos humanos, em uma concepção na qual a igualdade e diferença constituem-se valores imbrincados em consonância com a equidade, tendo como premissa "circunstâncias históricas da produção da exclusão, dentro e fora da escola", tal como preceitua Brasil (2008, p. 5).

Verifica-se, desse modo, que a educação inclusiva, em consonância com o direto à educação, extensivo a todos os estudantes, indistintamente, preconiza que tal direito deve ser estendido tanto aos alunos com deficiência como àqueles sem deficiência alguma. Neste sentido, independentemente de sua condição, os estudantes constituem-se sujeitos de direitos. A despeito disto, há que se considerar que os dispositivos legais, por si só, não possibilitam oportunidades, em nível de igualdade para todos, como preconizado na Constituição Federal Brasileira (BRASIL, 1988).

$\mathrm{Na}$ atualidade, ainda é possível observar, que as pessoas com deficiência, de modo geral, ainda são estigmatizadas e em muitos momentos segregadas em razão de sua condição, o que faz com que estas se isolem socialmente. Para Sawaia (200I, p. 8):

[...] a exclusão é processo complexo e multifacetado, uma configuração de dimensões materiais, políticas, relacionais e subjetivas. É processo sutil e dialético, pois só existe em relação à inclusão como parte constitutiva dela. Não é uma coisa ou um estado, é processo que envolve o homem por inteiro e suas relações com os outros.

Nesse sentido, compreende-se que existam diferentes maneiras de exclusão, chamando-se a atenção para o fato de que mesmo no contexto de ações inclusivas, distintas formas de exclusão possam se apresentar. No cenário da sala de aula, por exemplo, um professor que não adequa uma determinada atividade ao aluno que tenha uma especificidade educacional exclui este aluno tanto no que concerne aos espaços físicos da escola, como no que diz respeito à construção de conhecimentos. Há ainda, por parte de muitos pais, a atitude de infantilizar a criança ou jovem, o que ocorre em razão de suas 
deficiências, configurando-se em isolá-lo, pois segundo pontua Mazzotta (200I) pessoas com deficiências possuem suas potencialidades, sem precisar que sejam tidas como coitadas e ou crianças incapazes.

Desse modo, a Educação Especial na "perspectiva da educação inclusiva busca superar a visão do caráter substitutivo da Educação Especial ao ensino comum, bem como a organização de espaços educacionais separados para alunos com deficiência” (SILVA, 2013, p. 160). Esta se constitui como uma educação que tenciona ao atendimento destes estudantes, preferencialmente dentro do espaço da sala de aula comum, adotando um conceito de interação, onde, a partir desta, os diferentes sujeitos reconstroem a si e ao mundo do qual fazem parte.

Ainda em se tratando destas abordagens conceituais, Brasil (2008, p. II) discorre que a Educação Especial, no âmbito da política de Educação Inclusiva, tem como premissa o fato desta se constituir enquanto modalidade de ensino ao longo dos níveis e etapas. Assim sendo, o apoio por meio do Atendimento Educacional Especializado (AEE) oportuniza o uso de recursos e serviços, ao longo de todo o processo de ensino e de aprendizagem, em turmas regulares. À luz destas considerações, Glat, Pletsch e Fontes (2007, p. 344) evidenciam:

A Educação Especial tradicionalmente se configurou como um sistema paralelo e segregado de ensino, voltado para o atendimento especializado de indivíduos com deficiências, distúrbios graves de aprendizagem e/ou de comportamento, e altas habilidades. Contudo, a partir das últimas décadas, em função de novas demandas e expectativas sociais, os profissionais da área têm se voltado para a busca de outras formas de educação escolar com alternativas menos segregativas de absorção desses educandos nas redes de ensino.

Diante da assertiva, entende-se que as questões sociais e a conscientização da necessidade de ações pedagógicas específicas aos estudantes com necessidades educacionais especializadas tem envolvido profissionais diversos, mesmo não sendo ainda de forma excepcional, todavia observa-se, como exposto no excerto, que transformações nesse sentido, destacam ainda um ponto crucial referente ao fato de que tal modalidade permeia todas as etapas de escolarização dos indivíduos que dela necessitam, dotando-lhes do direito de receber o serviço de AEE, a se realizar de forma integral e ou transversal no âmbito do sistema regular de ensino, desmistificando concepções segregadoras, em relação ao estudante com deficiência. 
Assim, tendo em vista que neste trabalho abrange especificamente, o ensino superior e as entrevistas realizadas com estudantes surdos que utilizaram a $\mathrm{EaD}$, em cursos de formação nessa modalidade, torna-se pertinente destacar que a Lei de Diretrizes e Base da Educação Nacional (LDB), em seu Artigo 58, capítulo $3^{\circ}$, declara que as instituições devem ofertar a educação especial desde a educação infantil, estendendo-se ao longo da vida (BRASIL, 1996). Desse modo, mesmo a Universidade sendo um ambiente mais autônomo em comparação à educação básica, torna-se necessário dispor de ferramentas para entrada e permanência de alunos com deficiência, de forma que seu processo educacional seja eficazmente desenvolvido, possibilitando a inclusão e participação de um contingente maior de pessoas.

\section{I EDUCAÇÃO INCLUSIVA NA ÁREA DA SURDEZ}

No que se refere à surdez, um importante dispositivo é a Lei №. 10.436/2002, popularmente conhecida como Lei da Libras que também marcou a década, pois a comunicação sinalizada do Brasil até então não era tida com status de língua, sendo oficialmente reconhecida como meio de comunicação e expressão da comunidade surda brasileira no ano de 2002 (BRASIL, 2002). Posteriormente, esta foi regulamentada pelo Decreto N. 5.626/2005, o qual dispunha sobre a língua de sinais, especificando vários aspectos no tocante aos profissionais habilitados a trabalhar com a Libras, entre estes, o professor e o profissional intérprete, importante recurso que intermedia a comunicação do surdo em sala de aula (BRASIL, 2005). Cabe destacar, que para desenvolvimento do trabalho na área, foi criada também, uma lei em 20ı, visando orientar estes profissionais que mediam a interação entre surdos e ouvintes, ou seja, a Lei №. 12.319/2010. (BRASIL, 2010).

Nessa acepção, o Decreto $\mathrm{N}^{\circ}$ 5.626, dispõe ainda sobre a disposição dos alunos em sala de aula e aptidões das instituições a fim de que possam receber os estudantes, propiciando-lhes a permanência nos espaços educacionais. Dos artigos 22 ao 24 a lei em questão discorre amiúde acerca da educação de surdos, orientando todos os níveis, inclusive sobre práticas que devem ser adotadas no contexto do ensino superior. (BRASIL, 2005).

Todavia, no tocante à educação básica, embora estes e outros dispositivos legais tenham buscado contribuir com os direcionamentos em relação à inserção da Libras em 
diferentes áreas, entre elas, a educacional, não se obteve resultados positivos na escolarização de discentes, sendo estes alunos-surdos.

Pereira (2009), analisando a escrita de alunos surdos em diversas escolas no Estado de São Paulo, o que se deu através de oficinas de Língua Portuguesa com textos produzidos por surdos dos níveis fundamental e médio, identificou muitas fragilidades no uso da língua portuguesa e, principalmente, pouca familiaridade com a linguagem escrita. Evidenciou-se ainda as vulnerabilidades dos discentes quanto ao processo de leitura.

A problemática acerca da não efetivação da Libras na educação de surdos, vem sendo recentemente discutida sob muitos vieses e, no que se refere às metodologias aplicadas em sala de aula, bem como às ações dos atores que atuam na área, em instituições de ensino, Falcão (2015) tece uma crítica a qual envolve o fato de professores e intérpretes tratarem surdos como incapazes, ofertando respostas de atividades, facilitando as provas escolares e os tratando como se não possuíssem pensamento reflexivo acerca dos conteúdos desenvolvidos em sala de aula. As concepções do autor trazem à tona uma questão muito importante, evidenciada por Mazzotta (200I), quando este discorre que as pessoas com deficiência não precisam ser infantilizadas e muito menos "que peguemos à mão", carecem verdadeiramente de suportes teórico e metodológico, para que de forma autônoma, sejam protagonistas de suas vidas.

As colocações de Mazzzotta (200I), para quem está fora do contexto de estudos de educação especial sob a perspectiva inclusiva, soam quase como de alto rigor, mas estas se constituem enquanto crítica essencial aos profissionais que trabalham com estes sujeitos. No contexto da surdez, houve um tempo em que os surdos foram estigmatizados e cerceados que qualquer atividade social, segundo afirma Strobel (2009), porém, na atualidade é preciso pensar que não será tratando-os como vítimas que desenvolverão suas habilidades e potencialidades educacionais.

Falcão (2015) destaca que a educação de surdos tem sido realizada na superficialidade, sem uma reflexão mais profunda; uma vez que o professor, de modo geral, quando pergunta se o aluno entendeu, já espera receber um "sim" a fim de conclua que o trabalho está feito. Sobre a questão, dispõe ainda que:

Ao permanecer alheio e na superficialidade dos saberes comuns do discurso simplista e retórico, com pouca maturidade intelectual, muita ingenuidade e até 
certo ponto, na mediocridade mental produzida pela sociedade de surdos e ouvintes que não exploram a capacidade do potencial cognitivo de cada sujeito. Segue-se a escolarização na inoperância do discurso que surdos aprendem igual aos ouvintes e que eles aprenderam o contexto. Se alguém duvidar eles respondem com o sinal "entender" e todos se calam. Ninguém segue a pergunta: "entender o que"? "Explique o que entendeu". "De que forma"? "Por que"? (FALCÃO, 2015, p. 394).

As críticas dispostas instigam reflexões pertinentes às formas de tratar estes alunos e de vê-los em sala, alçando perspectivas para além de uma obrigação definida juridicamente, pois é preciso conceber a questão enquanto uma responsabilidade social, permitindo o desenvolvimento integral do sujeito surdo. Infere-se assim, que a forma como a educação básica atua, em relação ao ensino de surdos, tem refletido nos níveis educacionais seguintes, conforme aponta Skliar (2016).

Assim, no tocante ao ensino superior, mesmo com as políticas educativas, ainda há um inexpressivo número de surdos que se fazem presentes. Esta questão vem sendo discutida por Santana (2016), Lacerda e Polleti (2009), assim como Lodi (2010). Os autores enfatizam as fragilidades que se arrastam desde a educação básica, as quais se tornaram latentes pela falta de metodologias que apoiem estes alunos, cabendo destacar que o termo apoiar, aqui utilizado, não significa promover o estudante de um ano para o outro, sem que este tenha desenvolvido as competências necessárias para essa promoção. A ação docente deve focar em intervenções que propiciem, do ponto de vista metodológico, um trabalho com os conteúdos a fim de que este busque garantir a efetiva aprendizagem do estudante surdo.

Três pontos destacados por Chahini (2016), no que se refere à educação de surdos no ensino superior, dizem respeito, primeiramente ao acesso, ou seja, à entrada destes alunos na universidade, pois é preciso que as avaliações sejam realizadas pela perspectiva de que o discente tem especificidades em sua escrita por exemplo, que o diferem de estudantes ouvintes, o que muitas vezes não é considerado. Em segunda ordem, refere-se à permanência destes alunos na academia, pois ainda é possível perceber ausência de conhecimentos de muitos docentes acerca da surdez, no intuito de proporcionar formas de aprendizagem que permitam um entendimento melhor dos conteúdos inerentes ao componente curricular, assim como ao ano escolar. Por fim, ou seja, em terceira ordem, destaca-se aspectos referente à fragilidade da intermediação linguística entre o intérprete e 
o docente, pois este profissional precisa entender o que foi dito para transmitir de forma clara, e não apenas traduzir palavras e expressões sem que estas façam sentido para o aluno surdo, torna-se, portanto, necessária a devida qualificação em prol de sua atuação no ensino superior.

Acerca de tais proposições, Bruno (20II) salienta que a democratização da educação superior no Brasil, no contexto de políticas públicas e ações de inclusão, enfrenta estes dois elementos: o acesso e a permanência de alunos surdos, exatamente na direção do que é demarcado por Chahini (2016).

A questão de educação de surdos no ensino superior foi investigada também por Santana (2016) que constata que a realidades destes alunos não se diferem muito do nível daqueles da educação básica, pois mesmo havendo políticas educativas, na prática poucos recursos são disponibilizados para a efetivação do processo educacional.

Considerando, pois, que a academia é também uma instituição transformadora, que se interliga às formas como os indivíduos se organizam socialmente e constroem seus princípios, Chauí (200I, p. 35) discorre que a "universidade não é uma realidade separada e sim expressão historicamente determinada de uma sociedade determinada", assim, é possível que se perceba questões tecidas por desigualdades que geram um sistema institucionalizado de exclusões diversas (culturais, sociais e políticas), sendo primordial que se repense a indiferença e a desigualdade que se colocam como grandes desafios a serem ultrapassados.

Nesta lógica, ainda que com muitas fragilidades e necessidade de redirecionamentos na estrutura curricular assim como em ações executadas no âmbito da sala de aula, alguns dispositivos têm proporcionado aproximação de surdos com os conteúdos acadêmicos, em busca de uma eficiência no tocante à aprendizagem do sujeito surdo, tais como os ambientes virtuais.

Como a discussão proposta neste trabalho focaliza a relação entre a educação de surdos e o ensino à distância, aponta-se, parafraseando Kenski (2007) que a tecnologia na educação constitui-se um processo de socialização inovador, com perfil acessível, proporcionando liberdade aos estudantes surdos, quer seja para sanar dúvidas ou para expor um posicionamento acerca de qualquer assunto abordado em aula, pois segundo afirma Rojo (2013), a esfera virtual é menos intimidadora nestas questões educacionais. 
Assim, sendo, no que se refere à modalidade de educação à distância, indiscutivelmente de uma forma geral, esta se tornou uma opção de fácil acesso, aproximando, a partir de recursos diversos os diferentes sujeitos, muitos dos quais possuem pouco tempo para cursos em modalidades presenciais. $\mathrm{A} \mathrm{EaD}$, teve um crescente número de adeptos nos últimos anos, o que vem se potencializando pelo público com algum tipo de necessidade educacional especializada.

\subsection{EAD: CONHECENDO O PROCESSO DE EDUCAÇÃO VIRTUAL}

A nomenclatura "à distância" remete, erroneamente no cenário da educação, a um pensamento de isolamento. Todavia, um aspecto interessante nesta modalidade é que pelo suporte de aparatos eletrônicos e pelo uso da internet tem sido possível superar o distanciamento físico, pois a interação é um fator recorrente nos espaços virtuais. Assim, tem-se utilizado o termo "educação à distância", mas a modalidade constitui-se, sobretudo, pela socialização de pessoas num campo virtual.

À guisa de se realizar um breve histórico acerca do surgimento da modalidade, Schlosser (2010) destaca que o contexto histórico da EaD pode ser dividido em diferentes gerações sendo que a primeira delas concerne ao estudo por correspondência, ocorrido nos séculos XVIII e XIX (I80o-1850). Nesse processo, os textos e as instruções eram entregues pelos correios, sendo aplicado pela primeira vez, nos Estados Unidos. A segunda geração está inserida na transmissão de conhecimentos, através do rádio e da televisão, datando do início do século XX (1900).

$\mathrm{Na}$ terceira geração se inserem as Universidades abertas, ao final de 1960; a quarta geração também é datada no século XX, mais precisamente entre as décadas de 1970 e 1980, sendo esta especificada pela interação entre o aprendiz e o conhecimento através de cursos por áudio e videoconferências transmitidos por telefone, satélite, cabo e rede de computadores; a quinta e última geração data do século $\mathrm{XX}$, iniciando em 1900 e se estendendo até os dias atuais, teve como característica principal o ensino e aprendizagem on-line em classes e universidades virtuais. (MUGNOL, 2009).

No que concerne ao Brasil, o marco significativo para o desenvolvimento, regulamentação, avaliação e supervisão da $\mathrm{EaD}$, em todos os níveis da educação brasileira, foi o artigo $\mathrm{n}^{\mathrm{o}} 8 \mathrm{o}$ da $\operatorname{LDB}$ 9.394/96, que apresentou a educação à distância como modalidade de ensino, em todos os níveis, com algumas exigências para a oferta de cursos, 
entre estas que a instituição de ensino estivesse credenciada pela União, a qual regulamentaria os requisitos para a realização de exames e registro de diploma, possuindo tratamento diferenciado, tais como: custos de transmissão, concessão e reserva de tempo, tendo finalidade exclusivamente educativa. (BRASIL, 1996).

Sua definição apresenta-se polissêmica em muitas literaturas contemporâneas, mas utilizando-se do que dispõe o Decreto №. 5.626/2005 tem-se que é uma modalidade de ensino on-line, sem contato físico, "na qual a mediação didática pedagógica nos processos de ensino e de aprendizagem ocorre com a utilização de meios e tecnologias de informação e comunicação, com estudantes e professores, desenvolvendo atividades educativas em lugares ou tempos diversos” (BRASIL, 2005, não paginado). Nesta acepção, percebe-se que a expressão $\mathrm{EaD}$ remete às noções de tempo, distância, educação e autonomia, ou seja, nessa modalidade de ensino o aluno passa a ter mais liberdade com horários e escolhas de local de acesso.

Atualmente, a EaD tem sido considerada como reflexo do avanço tecnológico da comunicação e informação, apresentando-se como novidade, segundo Rosin (2010), pelos cursos novos oferecidos que se iniciaram apenas como complementares e atualmente incluem formação de ensino superior e continuada. Assim sendo, pelos avanços dos aparatos tecnológicos (computadores, tabletes e celulares), assim como, a própria conexão virtual, qual a internet a partir da segunda metade do século $\mathrm{XX}$, a modalidade vem ganhando adeptos e conquistando espaço na esfera educacional, como pontua Schlosser (2010).

Tal modalidade de ensino compreende a participação de alguns atores essenciais nestes espaços educacionais virtuais, tais como os professores, tutores e coordenadores. Estes profissionais carecem de preparo tanto nas questões de suas específicas disciplinas, como no que concerne à familiaridade com a tecnologia (MUGNOL, 2009). Assim, o papel do professor desloca-se do contexto habitual da sala de aula e passa ao de interação com os alunos, por meio de outras formas e materiais tecnológicos, mediando a construção do conhecimento em uma esfera, que para muitos, constitui-se ainda desafiadora.

Junto ao trabalho do professor em $\mathrm{EaD}$, encontra-se a participação de um sujeito que facilitará o percurso do aluno nessa metodologia: o tutor. Este profissional é demarcado por Bernardino (20II) como um agente que intermedia o processo entre aluno e 
professor, permitindo a construção coletiva em ações, comunicacionais e organização de material, no espaço virtual, e entre outros.

A EaD se constitui enquanto forma de proporcionar o acesso rápido à informação para o conhecimento do indivíduo, por meio da tecnologia de forma interativa e ágil, permitindo uma ascensão social e incluindo o cidadão ao meio em que vive; segundo afirma Mugnol (2009). Neste sentido, discutir-se-á na seção seguinte aspectos de como esta inclusão, em modalidade virtual, se apresenta ao aluno surdo.

Retornando aos anos 2000, quando sugiram as primeiras televisões em sala de aula, ter o professor dentro do aparelho ao invés da sala, provocou um sentimento de euforia e preocupação, o que, mesmo por algum tempo se apresentando como um modelo desafiador, foi um sistema necessário à época, conforme apontam Draibe e Perez (1999).

Nesse sentido, é importante que se destaque algumas questões referentes à $\mathrm{EaD}$, as quais vêm sendo pontuadas por estudos tais como os de Oliveira (2013) e Mattar (2012), sendo estes: despreparo do educador, materiais com pouca qualidade, demora de respostas do professor ou de tutores e até conteúdos repassados de forma pouca dinâmica, mas que podem ser sanadas com base em feedback dos usuários, reclamações nos canais das instituições.

Todavia o sistema é visto na atualidade como um forte aliado às necessidades da efervescente sociedade do século XXI, como pontua Bernardino (20iI).

Nos ambientes virtuais, Silva (2011) destaca que o estudante, ao optar pela modalidade, muitas vezes, inicia as atividades educacionais ciente de que poderá enfrentar vantagens e desafios, pois, estudar frente a um computador ou em casa, com horários flexíveis exige: concentração, administração de tempo, conectividade com as redes sociais e disciplina, pois as vantagens devem ser aproveitadas e os desafios encarados e vencidos. No que diz respeitos aos sujeitos destas pesquisas, os desafios são ainda maiores, tendo em vista as necessidades educacionais especializadas, sendo estes os elementos que instigaram investigar, a partir dos alunos surdos, quais suas dificuldades e perspectivas acerca da questão e como essa modalidade tem sido, no contexto da surdez. 


\section{EAD E SURDEZ: DISCUTINDO A MODALIDADE DE ENSINO À DISTÂNCIA SOB A PERSPECTIVA DE ALUNOS SURDOS}

As novas tecnologias demonstram ser no âmbito educacional, ferramentas eficientes com significativas potencialidades, conforme aponta Dudeney (2016). Nesta direção, Lopes (2017), discorre que no contexto da surdez as tecnologias têm sido consideradas, por alunos portadores desta deficiência, como acessíveis visualmente, e que mesmo diante de algumas fragilidades estas têm aquinhoado um número significativo de adeptos surdos em virtude do uso de ambientes virtuais. Concorda-se assim, com Stumpf (2010, p. 02) ao afirmar que "do ponto de vista dos surdos o uso do computador e da internet inaugurou uma nova dimensão às suas possibilidades de comunicação, pois são tecnologias acessíveis visualmente”.

Neste sentido, buscou-se entender como os processos educacionais em modalidade a distância tem se desenvolvido em classes com alunos surdos. Assim, os participantes da pesquisa (em um total de 3) foram questionados (através de entrevista) se já haviam realizado algum curso do nível superior, tal como graduação, pós-graduação ou formação continuada em EaD, obtendo-se como resposta:

\section{ENTREVISTADO I}

Sim, já fiz Pós-graduação em tradução e interpretação em Libras em uma instituição do Sul, Rio grande do Sul, mas tranquei. Muito caro.

ENTREVISTADO 2

Sim, fiz, no Sul, especialização em Libras. Depois que formei na graduação fiz imediatamente uma pós.

ENTREVISTADO 3

Comecei a fazer graduação em uma instituição aqui de São Luís, mas parei porque iniciei o curso na UFMA, era graduação em Pedagogia à distância.

Com base neste primeiro relato, observou-se que assim como afirma Goes (2010) o ensino a distância tem despertado o interesse de estudantes surdos, que em geral, optam pela modalidade $\mathrm{EaD}$, a partir da formação inicial, sendo este também, o motivo pelo qual escolheu-se investigar esta modalidade de ensino, pois como já demarcado anteriormente, pela educação básica perpassam muitas fragilidades e o conhecimento de aspectos da Língua Portuguesa, nesse nível, ainda é insuficiente para a autonomia em ambientes virtuais. 
Diante do colocado, nota-se que o interesse nos cursos em $\mathrm{EaD}$ se deram, em maioria, na área da Libras, o que chama a atenção para as colocações de Ferreira, Lopes e Tolomei (2019) quando discorrem que a Língua Brasileira de sinais assume papel relevante nas relações sociais dos surdos, garantindo participação ativa destes sujeitos em diversos âmbitos sociais, oportunizando autoconfiança e preservação de sua identidade cultural.

$\mathrm{Na}$ busca de melhores condições no mercado de trabalho, os surdos têm escolhido opções que os aproximem de atividades que lhes permitam atuar, utilizando a Libras, conforme demarca Falcão (2015). Este ressalta ainda a necessidade de um ambiente no qual o surdo tenha capacitação para desenvolver tarefas e compreensão acerca de suas especificidades, podendo ser esta a motivação para tais sujeitos buscarem formações na área das Libras.

À guisa de ampliar o entendimento acerca das questões educacionais inclusivas em $\mathrm{EaD}$, perguntou-se o motivo da escolha de cursos nesta modalidade e como foi a adaptação no ambiente virtual, ao que os estudantes discorreram:

Escolhi porque foi no ano de 2014, eu formei na UFMA e queria fazer pósgraduação. A graduação era em outra área e escolhi pós em Libras. Para mim era muito fácil, simples. Tinha tutor para tirar dúvidas que entendiam também sobre a Libras. Era normal, simples, tinha tutor surdo e slides explicativos. Eu já usava português nas atividades acadêmicas, então ler o conteúdo foi simples. Parecia com o Sigaa ${ }^{3}$ os professores cadastravam atividades e nós precisávamos fazer. $\mathrm{O}$ contato era por mensagem, e-mail e assim foi simples, só parei pelo aspecto financeiro mesmo.

\section{ENTREVISTADO 2}

Eu já tinha formação em pedagogia e objetivava ser professor de níveis maiores, assim, experimentei EAD porque sendo campo visual eu poderia acompanhar melhor, pois tive algumas dificuldades na graduação, por questões da oralidade. Escolhi esta modalidade porque pensei que pudesse ser melhor e foi. É igual o sistema integrado de atividades da UFMA; ou seja, era o ambiente, igual. Eu não achava difícil. Professores sabiam que eu era surdo, e isso era importante porque eu escrevia um pouco fragilizado o Português, mas sempre tirei dúvidas, e esclarecia tudo. Até a comunicação, sendo escrita eu lia e me comunicava, melhor do que se fosse professor falando tentando me fazer entender leitura labial.

\section{ENTREVISTADO 3}

Escolhi porque sempre que eu fazia ENEM eu não conseguia muitos pontos. Não passava no ENEM. Então, escolhi a experiência com a modalidade à distância. Cursei a graduação três meses somente e não achei difícil. Não tinha janela de

\footnotetext{
3 Sistema Integrado de Gestão de Atividades Acadêmicas da Universidade Federal do Maranhão 
Libras, mas a comunicação era acessível pelas leituras. Depois eu passei no vestibular específico Letras-Libras da UFMA e cancelei a graduação EaD.

Os entrevistados I e 2 relataram a escolha pela pós-graduação à distância, após finalizarem suas graduações, almejando aprimorar o currículo e destacaram que o processo se deu sem muitas dificuldades. Relataram também, que pela aproximação com o a língua portuguesa em modalidade escrita, a comunicação aconteceu de forma mais eficiente, corroborando para as colocações de Fernandes (2014) que evidencia a importância da escrita, para inclusão do surdo em atividades sociais diversas.

Estas colocações permitem ainda, uma reflexão acerca da importância de estudantes surdos estarem em sala inclusiva, sob uma perspectiva bilíngue, pois, segundo afirma Lodi (2013) é imprescindível observar a organização, em diferentes níveis de educação, com maior atenção à escrita da Língua Portuguesa e sua apresentação aos alunos e como esta pode ser trabalhada com eles. No ensino superior, por exemplo, pressupõe-se que este aluno tenha um conhecimento maior acerca da escrita, mas ainda assim possui algumas dificuldades, sendo necessário que se adapte metodologias e recursos a fim de fazê-los alcançar os conhecimentos educacionais, sobretudo nos ambientes virtuais, onde comunicar-se pela escrita é a forma predominante.

Lodi (2013, p. 54) salienta ainda que o a língua portuguesa em seu formato escrito, dentro dos processos educacionais, "é decorrente da organização pedagógica, na medida em que as atividades, os textos complementares à sala de aula e os livros didáticos indicados para leitura são escritos em português, o que lhe garante também status de língua de instrução”. Nesta acepção, a partir dos relatos dos entrevistados compreende-se que a apropriação dos textos e entendimentos dos conteúdos em EAD, acontecem também por meio da consciência de singularidades da escrita destes alunos, as quais poderão ser reorganizados pelos professores.

Outro ponto exposto pelo entrevistado 2, traz à tona uma comparação entre a modalidade presencial e a $\mathrm{EaD}$ ressaltando a escrita em relação à oralidade no trecho em que o estudante menciona que a leitura labial se tornava, em alguns momentos, falha. Pensa-se diante do colocado que no formato escrito os conteúdos se tornam eficientes pela materialidade da escrita, podendo este ser consultado posteriormente, enquanto pela 
oralização em sala de aula, muitas vezes são perdidas informações transmitidas pelo professor, como dispõem os estudos de Skliar (2016).

Torna-se relevante destacar que tanto em ambientes presenciais, como virtuais o professor é um agente essencial para que a educação de surdos seja concretizada e no que concernem aos elementos de $\mathrm{EaD}$, ressalta-se que o professor nesta modalidade é o principal responsável em tornar exequível o processo de ensino e de aprendizagem a partir da seleção de conteúdos, materiais didáticos e também, pelo conhecimentos dos alunos e suas especificidades, "fazendo os ajustes necessários; estimular a interação e, sobretudo, estimular a apresentação, discussão e possíveis soluções de problemas reais e projetos” (GIUSTA, 2003, p. 27).

Inferiu-se ainda, a partir do relato do entrevistado 3, que a escolha pela $\mathrm{EaD}$ se motivou a partir dos entraves surgidos. No tocante ao ingresso no ensino superior, esse sujeito, que quase sempre impossibilitado pelas dificuldades da Educação Básica não consegue cursar uma graduação presencial, o que já vem sendo demarcado por muitos autores da área, tais como Falcão (2015), Fernandes (2014), Lodi (2013), Bruno (2011), entre outros.

Vale destacar que o vestibular mencionado pelo entrevistado 3 trata-se do curso de Letras-Libras da Universidade Federal do Maranhão (UFMA), que foi incluído na instituição no ano de 2015, apesar de, em contexto nacional, ter surgido em 2006, segundo afirmam Quadros e Stumpf (2009) através do pioneirismo da Universidade Federal de Santa Catarina.

Todos os entrevistados acordaram que não sentiram grandes dificuldades, ratificando as palavras de Lopes (2017) que dispõe sobre a aceitação de alunos surdos sobre a escolha por cursos em EaD, haja vista, esta modalidade constituir-se em grande potencialidade de acesso educacional aos surdos, indo ao encontro das proposições de Pivetta, Saito e Ulbricht (2014) que investigaram o processo de inclusão de surdos em ambientes virtuais, constatando que embora existam algumas debilidades no sistema, tais como, lentidão e funcionalidades do hardware, ainda assim, muitos surdos relataram ser esta uma modalidade bem recebida por eles, haja vista suas limitações físicas. 
Buscou-se ainda identificar de forma específica, quais dificuldades poderiam ser destacadas, ou ainda a sugestão de mudanças no ambiente virtual com especificações, ao que os entrevistados responderam:

\section{ENTREVISTADO I}

Não tive experiências difíceis na pós-graduação à distância. Meu instrutor era surdo também, ajudou muito.

\section{ENTREVISTADO 2}

Foi uma etapa sem muitas dificuldades. Plataforma foi fácil manusear. A observação que eu faço é mais sobre a possibilidade de mais vídeos em Libras. Mas nada foi difícil, normal.

\section{ENTREVISTADO 3}

Minha sugestão é ter mais atividades em Libras pois ao me matricular informei minha especificidade. A Libras é a língua que o surdo usa e é importante. Não atrapalhou enquanto estudei à distância, mas poderia ter mais Libras.

No que concerne aos aspectos relacionados à comunicação, a pessoa surda apresenta peculiaridades quanto à linguagem. Sua língua em modalidade espaço-visual permite comunicação e identificação nos meios os quais estes sujeitos estejam inseridos, como aponta Skliar (2016), sendo este um aspecto demarcado nos relatos, em especial, na fala do entrevistado I, o qual destacou o fato do seu tutor ser surdo, tornando a modalidade a distância mais familiar a partir da identificação com o profissional em EaD. Logo, nos espaços educacionais a distância, este importante agente, quando com as mesmas especificidades do estudante surdo, poderá compreender melhor as dificuldades.

Os entrevistados 2 e 3 destacaram a importância de mais elementos visuais e sugeriram que a presença da Libras nos espaços virtuais poderia ser repensada, embora este fato não tenha dificultado em nenhum aspecto, o percurso do curso. Ainda assim, destacase que esta peculiaridade da educação de surdos precisa ser considerada, tanto para que possam alcançar mais estudantes na modalidade, como para tornar o ambiente favorável à permanência dos indivíduos nos cursos, pois segundo afirma Kenski (2007) a ausência de conhecimentos, acerca das particularidades dos alunos, gera desistência e desânimo nas plataformas digitais educacionais.

Nessa direção, Silva (2orI) concorda que a apropriação dos alunos surdos com os ambientes virtuais tem sido significativamente notada, destacando a potencialidade desta forma de educação em propiciar possibilidades permeadas pela identidade visual e 
identificação através da utilização da língua de sinais. Chahini (2016) também discorre acerca da relevância da instituição identificar as necessidades dos alunos com necessidades especiais desde a seleção do vestibular, a fim de acolhê-los não somente pelas paredes físicas da universidade, mas pela oportunidade de permitir que o processo educacional seja exequível.

Quando perguntados se fariam novamente algum curso de graduação, pósgraduação ou de formação continuada pelas plataformas $\mathrm{EaD}$, obteve-se como resposta os relatos a seguir:

\section{ENTREVISTADO I}

Sim, faria. Este ano estou finalizando outra graduação que é também da área de Libras e agora quando colar grau, depois da formatura vou procurar. Inclusive os preços estão mais acessíveis. Preciso de uma pós-graduação da área de educação, pois agora serei professor e quero atuar.

ENTREVISTADO 2

No momento estou buscando o mestrado, mas educação à distância é uma modalidade que o surdo se sente incluído, porque naquele ambiente a comunicação é, em maior parte, pela escrita, então nunca me senti excluído.

\section{ENTREVISTADO 3}

Sim. Fiz um curso de idioma recentemente e depois da minha graduação finalizada eu posso pensar em pós-graduação à distância, sim. Não vejo problema.

As respostas dos entrevistados indicaram boa aceitação da modalidade EaD. O entrevistado 2 referiu-se ao ambiente virtual como inclusivo, pois no momento de uso das plataformas institucionais, o que predomina é a escrita de modo que a comunicação é realizada de forma eficiente. Á luz dessas considerações, Santana (2016) destaca que a escrita de sujeitos surdos pode ser compreendida, se a estes forem proporcionadas metodologias que os alcancem, visto que, no caso dos participantes da pesquisa a leitura já era uma prática comum pois dois dos entrevistados já haviam concluído a primeira graduação.

O sentimento de exclusão é algo recorrente nos espaços presenciais, uma vez que muitos estudantes surdos vêm demarcando situações de não entendimento quanto aos conteúdos ou de comunicação falha com professores e intérpretes, todavia este fato não foi observado nos relatos dos participantes, no que se refere à $\mathrm{EaD}$. Sendo assim, reflete-se a partir de Lopes (2017, p. Io) quando este dispõe que "no passado, o objetivo do uso das ferramentas tecnológicas na educação de surdos era de 'corrigir a surdez', hoje, porém, 
mais do que oferecer assistência às necessidades, o uso da tecnologia visa auxiliar no desenvolvimento do potencial cognitivo[...], linguístico e socioafetivo”.

Todos responderam positivamente à pergunta se optariam novamente por um curso em $\mathrm{EaD}$ ratificando as proposições de Lévy (20II), de que não se deve temer as tecnologias e o virtual, sendo importante absorver o lado positivo e utilizá-lo para sobrevivência em sociedade. Nesse sentido, infere-se que os surdos estão aproximando-se das tecnologias, e considerando as experiências inclusivas, diferentemente daquelas vivenciadas em espaços presenciais, como bem afirma Falcão (2015).

Considerando, pois que segundo Sá (2016) a comunidade surda encontra muitas barreiras de inclusão, haja vista suas limitações comunicacionais e a ausência de recursos que possibilitem sua atuação em sociedade, perguntou-se quais instruções dariam a um amigo surdo caso este optasse por realizar um curso à distância e que considerações poderiam fazer sobre a $\mathrm{EaD}$, ao que os estudantes responderam:

\section{ENTREVISTADO I}

Sem preocupação. Fácil de fazer as atividades, se o surdo souber escrita do Português consegue sim, normal. Os slides conseguem fazer entender conteúdo, muito simples, normal. Indicaria sim ao amigo surdo porque não tem problema em educação à distância. A libras precisa ser língua do surdo, no caso de encontro presencial, com a participação de intérprete se houver necessidade, aí, é da instituição, porque é direito do surdo.

\section{ENTREVISTADO 2}

O surdo precisa estudar para conseguir viver sem depender do governo e de auxílio, eu vi no ensino à distância uma forma de melhorar meu currículo. Eu sempre indico aos amigos que estudem. Em EaD, indico também muito bom, ensino inclusivo. Tudo precisa ser melhorado, assim como na modalidade presencial, então, alguns problemas, pequenos, mas bom, simples, ensino normal.

\section{ENTREVISTADO 3}

Indicaria sim. É importante estudar. EAD é um modelo de educação que não deixa o surdo tão excluído. Precisa entender leituras, textos, etc., mas nós precisamos buscar, interagir. Indicaria para um amigo surdo fazer sim, importante.

O entrevistado I evidenciou a praticidade da modalidade $\mathrm{EaD}$, demarcando que a Libras é importante para o surdo caso sejam necessários encontros presenciais. Este também se mostrou ciente de que o intérprete de Libras é um agente importante na comunicação, demarcando que é um direito. $\mathrm{O}$ entrevistado 2 apresentou um trecho muito interessante quando este asseverou que o surdo precisa estudar para não depender de 
auxílios governamentais, a fim de ter mais autonomia, como vem apontando os estudos de Falcão (2015).

O entrevistado 2 segue discorrendo que o curso em EaD contribuiu para construção do seu currículo e relata que a modalidade é inclusiva. Entrevistado 3 também afirmou que é um ambiente inclusivo, ratificando as colocações de Matuzawa et al. (2003) quando estes dispõem que o ambiente virtual representa para tais alunos uma nova maneira de integrarse à sala de aula e que a educação à distância transformou a forma como os surdos socializam com os professores e demais colegas em ambiente virtual.

Quando os entrevistados discorreram que indicariam a modalidade de ensino aos seus pares, aproxima-se a reflexão de Sá (2016) acerca da comunidade surda e sua apropriação com atividades majoritárias de ouvintes a partir das possibilidades a eles viabilizadas, de modo que tais aptidões no ensino $\mathrm{EaD}$ constituem-se aos estudantes surdos uma opção a mais para progresso nos processos educacionais, o que permite a compreensão de que estes estudantes identificaram nas plataformas um meio propiciador de alcance aos conhecimentos acadêmicos.

Diante do exposto, pelos estudantes surdos, notou-se que as perspectivas positivas relacionadas à $\mathrm{EaD}$ podem ser motivadas pela justificativa destes sujeitos terem se sentido incluídos em suas experiências virtuais acadêmicas, assim como a disponibilização de acesso aos conteúdos de modo descomplicado, pois como afirma Kenski (2007) o abandono em plataformas virtuais de ensino acontece, em sua maioria, por insatisfação com conteúdos por parte de alunos ou inadequação aos espaços virtuais.

\section{${ }_{4}$ CONSIDERAÇÕES FINAIS}

O ensino a distância é uma ferramenta de grande impacto no contexto da inclusão social, cumprindo um papel basilar na redução das desigualdades, sejam elas sociais ou mesmo de outra ordem, como a educacional. Sua importância se dá na medida em que esta prepara o indivíduo para o exercício da cidadania, através do enfrentamento das adversidades e preconceitos que se lhes apresentam cotidianamente.

$\mathrm{Na}$ busca pela consecução de uma política educacional que seja de fato inclusiva, surge a EaD que, ao mesmo tempo em que se constitui como meio a possibilitar o acesso à educação, constitui-se também como ferramenta a serviço da acessibilidade. A acessibilidade é resultante do uso da $\mathrm{EaD}$ junto ao estudante com deficiência, derrubando 
barreiras diversas que muitas vezes, impedem o indivíduo com deficiência de acessar a conhecimentos que, certamente, o colocariam no mesmo patamar dos outros discentes.

A exclusão digital e a falta de investimento, que dizem respeito tanto aos governos quanto às instituições que oferecem cursos à distância, são entraves que acabam por impedir a consecução de um trabalho que inclua o estudante. A discussão, em questão mostrou que a perspectiva de alunos surdos sobre a educação à distância é de um ambiente favorável à aquisição de conhecimentos de modo descomplicado e inclusivo.

No contexto da surdez, é relevante destacar que para ter sucesso o aluno precisa ser responsável pela sua própria aprendizagem e as instituições devem aproximar-se das necessidades dos alunos usuários das plataformas digitais, a fim de proporcionar, a estes sujeitos, educação inclusive nos espaços virtuais.

\section{REFERÊNCIAS}

ALVES, L. Educação à distância: conceitos e história no Brasil e no mundo. Revista da Associação Brasileira de Educação à Distância, [s. l.], v. Io, p. 83-92, 20Ir. Disponível em: http://www.abed.org.br/revistacientifica/Revista_PDF_Doc/20II/Artigo_07.pdf. Acesso em: Io jun. 2020.

BERNARDINO, H. S. A tutoria na EaD: os papéis, as competências e a relevância do tutor. Revista Científica de Educação à distância, [s. l.], v. 2, n. 4, 20Ir. Disponível em: https://periodicos.unimesvirtual.com.br/index.php/paideia/article/view/r66. Acesso em: I5 jun. 2020.

BRASIL. Constituição da República Federativa do Brasil de 1988. Brasília: Senado Federal, 1998. Disponível em: http://www.planalto.gov.br/ccivil_03/constituicao/constituicaocompilado.htm. Acesso em: 5 jun. 2020.

BRASIL. Decreto № 7.6II de 17 de novembro de 20Ir. Dispõe sobre a educação especial, o atendimento educacional especializado e dá outras providências. Brasília: Presidência da República, 20Ir. Disponível em: https://www.fnde.gov.br/index.php/legislacoes/decretos/item/3179-decreto-n\%C2\%BA76II-de-17-de-novembro-de-2011. Acesso em: 5 jun. 2020.

BRASIL. Decreto-Lei no 5.626, de 22 de dezembro de 2005. Regulamenta a Lei no 10.436 , de 24 de abril de 2002, que dispõe sobre a Língua Brasileira de Sinais. Brasília: Presidência da República, 2005. Disponível em: http://www.planalto.gov.br/ccivil_03/_Ato20042006/2005/Decreto/D5626.htm. Acesso em: 5 jun. 2020. 
BRASIL. Lei № 9.394, de 20 de dezembro de 1996. Lei de Diretrizes e Bases. Brasília: Presidência da República, $1996 . \quad$ Disponível em: http://www.planalto.gov.br/ccivil_03/leis/19394.htm. Acesso em: ro jun. 2020.

BRASIL. Lei no $\mathbf{1 0 . 4 3 6}$, de 24 de abril de 2002. Dispõe sobre a Língua Brasileira de Sinais. Brasília: Presidência da República, 2002. Disponível em: http://www.planalto.gov.br/ccivil_03/leis/2002/1ro436.htm. Acesso em: 5 jun. 2020.

BRASIL. Lei no ${ }^{12.319}$, de $\mathbf{I}^{\circ}$ de setembro de 2010. Regulamenta a profissão de Tradutor e Intérprete da Língua Brasileira de Sinais. Brasília: Presidência da República, 2oro. Disponível em: http://www.planalto.gov.br/ccivil_03/_ato2007-2010/2010/lei/112319.htm. Acesso em: 5 jun. 2020 .

BRASIL. Ministro da Educação. Política Nacional de Educação Especial na perspectiva da educação inclusiva. Brasília: Grupo de Trabalho da Política Nacional de Educação Especial, jan. 2008. Disponível em: http://portal.mec.gov.br/arquivos/pdf/politicaeducespecial.pdf. Acesso em: 5 jun. 2020.

BRUNO, M. M. G. Políticas afirmativas para a inclusão do surdo no ensino superior: algumas reflexões sobre o acesso, a permanência e a cultura universitária. Revista Brasileira de Estudos Pedagógicos, Brasília, v. 92, n. 232, 20II. Disponível em: http://www.rbep.inep.gov.br/ojs3/index.php/rbep/article/view/3600/3335. Acesso em: 10 jun. 2020 .

CHAHINI, T. H. C. O percurso da inclusão de pessoas com deficiência na educação superior. Curitiba: Appris, 2016.

CHAUÍ, M. Escritos sobre a universidade. São Paulo: UNESP, 20oI.

DRAIBE, S. M; PEREZ, J. R. R. O programa TV escola: desafios à introdução de novas tecnologias. Cadernos de pesquisas, [s. l.], n. 6, 1999. Disponível em: https://www.scielo.br/pdf/cp/nio6/nio6ao2.pdf. Acesso em: is jun. 2020.

DUDENEY, G. Letramentos digitais. São Paulo: Parábola Editorial, 2016.

ELIAS, C. S. R.; SILVA, L. A.; MARTINS, M. T. S. L.; RAMOS, N. A. P.; SOUZA, M. G. G.; HIPÓLITO, R. L. Quando chega o fim? Uma revisão narrativa sobre terminalidade do período escolar par alunos deficientes mentais. Revista eletrônica saúde mental. [s. l.], n. $8, \quad$ v. $\quad \mathrm{I}, \quad$ jan./abr. 2012. Disponível em: https://www.redalyc.org/pdf/803/80323610008.pdf. Acesso em: 5 jun. 2020.

FALCÃO, L. A. B. Educação de surdos: comportamentos, escolarização e o mercado de trabalho. Recife: Ed do autor, 2015.

FERNANDES, S. Letramentos na educação bilíngue para surdos: caminhos para a prática pedagógica. Educar em Revista, Curitiba, n. 2, p. 51-69, 2014. Disponível em: https://www.scielo.br/pdf/er/nspe-2/o5.pdf. Acesso em: io jun. 2020. 
FERREIRA, H. J. G. P; LOPES, G. K. F.; TOLOMEI, C. N. Literatura surda: expressão da cultura surda. In: LOPES, G. K. F. (org.). Libras, linguagem e literatura: interfaces da identidade cultural surda. São Paulo: Mentes Abertas, 2019.

GIUSTA, A. S. Educação à distância uma articulação entre a teria e a prática. Belo Horizonte: Ed. PUC Minas, 2003.

GLAT, R.; PLETSCH, M. D.; FONTES, R. S. Educação inclusiva e educação especial: proposta que se complementam no contexto da escola aberta à diversidade. Educação, [s. l.], v. 32, n. 2, 2007. Disponível em: https://periodicos.ufsm.br/reveducacao/article/view/678. Acesso em: 5 jun. 2020

GOES, C. G. G. Curso de Letras/Libras: análise das experiências dos alunos surdos no ensino à distância do Rio Grande do Sul. 2oro. Dissertação (Mestrado em Educação) Universidade Federal do Rio Grande do Sul, Porto Alegre, 2010. Disponível em: https://www.lume.ufrgs.br/handle/ro183/29307. Acesso em: I5 jun. 2020.

KENSKI, V. M. Educação e tecnologias: o novo ritmo da informação. Campinas: Papirus, 2007 .

KIERKERGAARD, S. Qual a diferença entre educação especial e educação inclusiva? In: PRIOSTE, C.; RAICA, D.; MACHADO, M. L. G. (orgs.). Dez questões sobre educação inclusiva da pessoa com deficiência mental. São Paulo: [s. n.], 2006.

LACERDA, C. B. F.; POLlETI, J. E. Tornar a educação inclusiva. In: OSMAR F.; FERREIRA, W. (Orgs). A escola inclusiva para surdos: a situação singular do intérprete de Língua de Sinais. Brasília: UNESCO, 2009.

LÉVY, P. O que é o virtual?. São Paulo: Editora 34, 2011.

LODI, A. C. B. Educação bilíngue para surdos e inclusão segundo a Política Nacional de Educação Especial e o Decreto no 5.626/o5. Educação e Pesquisa, São Paulo, v. 39, n. I, p. 49-63, 2013. Disponível em: https://www.scielo.br/pdf/ep/v39ni/v39niao4.pdf. Acesso em: Io jun. 2020 .

LOPES, G. K. F. O uso das tecnologias no processo de ensino e de aprendizagem do surdo: libras em educação a distância. Revista Virtual de Cultura Surda, [s. l.], v I, n. 20, 2017. Disponível em: https://editora-araraazul.com.br/site/admin/ckfinder/userfiles/files/2\%C2\%BA\%2oArtigo\%2ode\%20Gerison \%20Kezio\%2oFernandes\%2oLopes.pdf. Acesso em: ı jun. 2020.

MARCONI, M. A.; LAKATOS, E. Fundamentos de Metodologia Científica. 8. ed. São Paulo: Atlas, 2017

MATTAR, J. Tutoria e interação em educação à distância. São Paulo: Learning, 2012.

MATUZAWA, F. L.; DElPiZZO, G. N.; MEDEIROS, M. E. S.; COSTA, A. M. B. Educação de Surdos do Curso de Pedagogia a Distância da UDESC: uma experiência da 
integração de equipes no uso do ambiente virtual de aprendizagem. In: Workshop de Informática na Escola, 9., [s. l.], 2003. Anais [...]. [s. l.]: Open Journal Systems, 2003. Disponível em: https://www.br-ie.org/pub/index.php/wie/article/view/779. Acesso em: Io jun. 2020.

MAZZOTTA, M. J. S. Educação Especial do Brasil: história e política pública. 3. ed. São Paulo: Cortez, 200I.

MENDES, E. G. Breve Histórico da Educação Especial no Brasil. Revista Educación y Pedagogía, [s. l.], v. 22, n. 57, 2010. Disponível em: https://revistas.udea.edu.co/index.php/revistaeyp/article/view/9842. Acesso em: 5 jun. 2020 .

MIRANDA, A. A. B. História, deficiência e Educação Especial. 2003. Disponível em: https://docplayer.com.br/8634951-Historia-deficiencia-e-educacao-especial-I.html. Acesso em: 5 jun. 2020.

MUGNOL, M. A educação a distância no Brasil: conceitos e fundamentos. Revista Diálogo Educacional. Curitiba, v. 9, n. 27, p. 2009. Disponível em: https://periodicos.pucpr.br/index.php/dialogoeducacional/article/view/3589. Acesso em: I5 jun. 2020.

OLIVEIRA, D. S. O uso do vídeo em EAD: desafios no processo de ensino aprendizagem Revista Cesuca Virtual: conhecimento sem fronteiras. [s. l.], v.I, n. I, 2013. Disponível em: http://ojs.cesuca.edu.br/index.php/cesucavirtual/article/view/422. Acesso em: is jun. 2020 .

PEREIRA, M. C. C. Leitura, escrita e surdez. 2. ed. São Paulo: FDE, 2009.

PIVETTA, E. M.; SAITO, D. S.; ULBRICHT, V. R. Surdos e Acessibilidade: Análise de um Ambiente Virtual de Ensino e Aprendizagem. Revista Brasileira de Educação Especial. Marília, v. 20, n. I, p. I47-I62, 2014. Disponível em: https://www.scielo.br/pdf/rbee/v2oni/ariv2oni.pdf. Acesso em: is jun. 2020.

QUADROS, R. M.; STUMPF, M. R. O primeiro curso de graduação em letras língua brasileira de sinais: educação a distância. ETD - Educação Temática Digital, Campinas, v.Io, n.2, p.169-185, 2009. Disponível em: https://periodicos.sbu.unicamp.br/ojs/index.php/etd/article/view/984. Acesso em: is jun. 2020.

RAIÇA, D.; OLIVEIRA, M. T. B. A educação especial do deficiente mental. São Paulo: EPU Edição, 2007.

ROGALSKI, S. M. Histórico do surgimento da Educação Especial. Revista de Educação do IDEAU. [s. l.], v. I, n., I2, 2010. Disponível em: https://www.caxias.ideau.com.br/wpcontent/files_mf/f6c2ec65b238dobd435622272470b9ddi68_r.pdf. Acesso em: io jun. 2020. 
ROJO, R. Escola conectada: os multiletramentos e as TICs. São Paulo: Parábola, 2013.

ROSIN, C. A. B. A educação à distância no Brasil: limites e possibilidades. 20 Io. Dissertação (Mestrado em Educação) - Universidade Metodista de São Paulo, São Paulo, 2oro. Disponível em: http://tede.metodista.br/jspui/handle/tede/irs6\#preview-linko. Acesso em: II jun. 2020.

SÁ, N. R. O discurso surdo: a escuta dos sinais. In: SKLIAR, C. (Org). A surdez: um olhar sobre as diferenças. Porto Alegre: Mediação ,2016.

SANTANA, A. P. A inclusão do surdo no ensino superior no Brasil. Journal of Research in Special Educational Needs, [s. l.], v. I6, n. I, 2016. Disponível em: https://onlinelibrary.wiley.com/doi/pdf/ro.1111/1471-3802.12128. Acesso em: ro jun. 2020.

SAWAIA, B. As artimanhas da exclusão: análise psicossocial e ética da desigualdade social. Petrópolis: Vozes, 200 I.

SCHLOSSE, R. L. A atuação dos tutores nos cursos de educação a distância. Revista Digital da CVA - Ricesu, [s. l. $]$, v. 6, n. 22, 2010. Disponível em: http://pead.ucpel.tche.br/revistas/index.php/colabora/article/view/128/112. Acesso em: Io jun. 2020.

SILVA, E. S. NOVA LDB comentada: atualizada com questões de concursos. 8. ed. São Paulo: Visão Global: Arte Editorial, 2013.

SILVA, R. A. F. Educação a distância e estudos surdos: experiências de acadêmicos surdos com as tecnologias. 20II. Dissertação (Mestrado em Educação) - Universidade Federal do Paraná, Curitiba, 20II. Disponível em: https://acervodigital.ufpr.br/handle/r884/27294. Acesso em: is jun. 2020.

SKLIAR, C. Os Estudos Surdos em Educação: problematizando a normalidade. In: SKLIAR, C. A Surdez: um olhar sobre as diferenças. 8. ed. Porto Alegre: Mediação, 2016.

STROBEL, K. História de educação de surdos. Florianópolis: Universidade Federal de Santa Catarina, 2009. Disponível em: http://www.libras.ufsc.br/colecaoLetrasLibras/eixoFormacaoEspecifica/historiaDaEduca caoDeSurdos/assets/258/TextoBase_HistoriaEducacaoSurdos.pdf. Acesso em: io jun. 2020 .

STUMPF, M. R. Educação de Surdos e Novas Tecnologias. Florianópolis: Universidade Federal de Santa Catarina, 2olo. Disponível em: http://www.libras.ufsc.br/colecaoLetrasLibras/eixoFormacaoPedagogico/educacaoDeSur dosENovasTecnologias/assets/719/TextoEduTecnologia__Texto_base_Atualizado_I_pdf. Acesso em: is jun. 2020.

UNITED NATIONS EDUCATIONAL, SCIENTIFIC AND CULTURAL ORGANIZATION. Declaração Mundial sobre educação para todos (Conferência de 
Jomtien). Brasília: UNESCO, I990. Disponível em: https://www.unicef.org/brazil/declaracao-mundial-sobre-educacao-para-todosconferencia-de-jomtien-1990. Acesso em: 15 jun. 2020.

UNITED NATIONS EDUCATIONAL, SCIENTIFIC AND CULTURAL ORGANIZATION. Declaração de Salamanca e de ação sobre necessidades educativas especiais. Brasília: UNESCO, 1994. 